\title{
LA LITERATURA COMO CASTIGO Sobre los problemas y contradicciones de la enseñanza de la literatura en los colegios públicos peruanos
}

\author{
Sr.Javier GarvichRebatta
}

\section{RESUMEN}

Que el nivel de la educación peruana está por los suelos no es ningún secreto. $Y$ menos secreto es la necesidad de un fortísimo desembolso de recursos para reconstruir -una vez más- el edificio de nuestro sistema educativo sobre los escombros de tres generaciones. Sin embargo, los grandes cambios educativos no solamente se producen por inyecciones de capital. Hemos olvidado que tenemos una estructura curricular impuesta por el Banco Mundial y que, si queremos una educación mucho más beneficiosa para nuestros hijos, merecería ser revisada. La actual enseñanza de la literatura, en cuanto a contenido $y$, sobretodo, praxis, es un buenejemplo.

\section{ABSTRACT}

The Peruvian education level is very poor and it is nota secret. Even more it is nota secret the need of an important outlay to reconstruct -once again- the building of our educational system over the debris of three generations. However, the significant educational changes are not only produced by capital injections. We have forgotten that the curricular structure was imposed by the World Bank and if we demand for a better education for our children, it will be necessary to review it. The current teaching of literature, regarding content, particularly its praxis, is a good example.

\section{PALABRAS CLAVE}

Literatura, enseñanza, canon literario, plan lector, lectura.

\section{KEYWORDS}

Literature, teaching, literary rule, reading plan, reading.

\section{I}

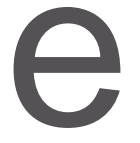

uando la literatura se integró con otras disciplinas y temáticas dentro de la macroasignatura "comunicación", uno suponía que se superaban efluvios decimonónicos y taxidermias inútiles. Que el estudiante supiera quela magia de la palabra iba desde la poesía amorosa hasta la crónica gamberra, pasando por elguión más jocoso. Sin embargo, como bien ha señalado Patricia Oliart ${ }^{1}$, el cambio de currículum sin una preparación docente, una campaña de motivación y un constante monitoreo termina siendo solo una mutación epidérmica. El enfoque constructivista de la educación, por poner un ejemplo, terminó encallando al ejercerse mecánicamente, bajo una vigilancia burocrática, sin los recursos que requería y aplicado por los docentes con un distanciamientorayano en el desdén.

La literatura se sigue enseñando como una disciplina altiva, distante y envarada. Al educando se le ofrece la literatura como un conjunto de grandes obras escritas genialmente por grandes personajes que nos miran desde arriba. Grandes escritos a los cuales hay que leer con reverencia, biografías de hombres que parecen haberlo hecho todo bien, enseñanzas y valores cursis 4ue se les ofrece sin ningún atractivo a nuestros niños y adolescentes . 
Se enseña la vida de Vallejo como la de un pobre desgraciado con cara de amargado, censurándole rigurosamente su activa vida política, de Ricardo Palma se les ofrece las tradiciones más ñoñas y edificantes, apenas se habla de nuestras escritoras a pesar que ellas virtualmente inauguraron la novela en el Perú. Incluso la enseñanza de José María Argüedas se hace hierática y distante, convirtiendo a uno de nuestros escritores más vivos en poco más que una momia quechua. Es el tono general, la enseñanza de literatura peruana termina siendo un obligado paseo entre cadáveres.

Nuestros escolares se saben de memoria "Los heraldos negros", se lo aprenden de paporreta y lo recitan -cada uno peor que el otro- en histéricos concursos de declamación. No importa, lo grave es que muy pocos entienden qué quiso decir Vallejo al hablar del "odio ele Dios", "los bárbaros atilas" o "la resaca ele todo lo sufrido". Al entender la poesía como declamación, la enseñanza de la poesía se pervierte . Entender la lírica como una artillería ele palabras tan floridas como complicadas o, peor aún, dando a entender que la gran poesía tiene que transcurrir entre los firmes pero estrechos canales de la rima y la métrica; es privarles a los jóvenes del real atractivo de la poesía o forzarles el gusto por lo impostado.

Esto lleva a algo peor, la ausencia de la poesía contemporánea en la actual enseñanza de nuestra literatura. Al parecer, la literatura peruana acaba con Vallejo y, en el mejor de los casos, con alguna poesía suelta ele Alejandro Romualdo o Arturo Corcuera. Así, pareciera que no solamente da miedo hablar de Hora Zero, sino que explicar a los chicos y chicas de quinto de secundaria la poesía ele Eielson o Watanabe causa puro pánico (¿Cómo enseñar algo que no conoces? ¿De verdad enseñan poesía moderna en las facultades e institutos de educación del Perú?),

Esa idea ele una poesía acartonada, cuando no fósil, provoca que el estudiante sienta repelencia hacia el acto poético y la creación literaria. Ignorando que cualquier adolescente -por obvios motivos- se siente impelido a hacer poesía por lo menos durante una vez en su vida; la enseñanza de la literatura le dice que hacer poesía es una acción aburrida, ajena, pretenciosa, falsa. Afortunadamente, a estas alturas del siglo y en las zonas urbanas, queda el atajo del rap, que ha estimulado entre los adolescentes y jóvenes un estilo de declamación rítmica, con versificación sincopada y temática agresivo - realista, obviamente fuera ele la observancia curricular.

Pero eso no pasa solamente con la poesía. La prosa tiene en la enseñanza ele la literatura similares problemas: prima la imagen que todo texto en prosa -más aún si es un cuento-debe ser una narración con mensaje, peor aún, con moraleja. Los exámenes de comprensión lectora guardan al final la inexorable pregunta ele ¿qué valores contiene el texto leído? Lo cual puede ser válido en una fábula ele Samaniego, pero francamente hilarante en un cuento de Bryce Echenique. Ver en cuentos y novelas textos ejemplarizaclores es retroceder siglos en el proceso literario, pretérito al tiempo ele Cervantes incluso. Lo peor es que si el estudiante quiere escribir una narración, desde ya se le está obligando a escribir no acerca de su vida, sus problemas o su autorreflexión ele los mismos; sino una prosa moralizante en peor sentido del término.

Es decir, la enseñanza convencional ele la literatura en el Perú convierte a la poesía en un baúl ele rimas tan coloridas como vacías (y huachafas). Y en prosa condena al texto en ser poco más que un panfleto propagandístico de valores del Occidente cristiano. Evidentemente, la enseñanza de la literatura no ha ele estar hecha para que todos los estudiantes salgan poetas o narradores, pero tiene que afirmar la necesidad de la literatura en sus vidas cotidianas; es decir, la necesidad de un consumo continuado de discursos que le interroguen, el texto como apoyo a la actitud crítica de las cosas, la literatura como una vía alternativa de creatividad y apropiación, así como el derecho de los niños y adolescentes al disfrute estético. Desgraciadamente, nada de eso puede lograr una literatura vista como un anaquel polvoriento de biografías y una hilera de textos de lectura tan obligatoria como ajena e inútil.

\section{II}

Un problema a contemplar es cuál es el canon literario que se ejerce en los colegios públicos. Hasta hace unos quince años todavía primaba un canon nacional-democrático que arrancaba con Garcilaso de la Vega, saltaba a Mariano Melgar, se entretenía con los textos más patrióticos de Ricardo Palma, alcanzaba a Vallejo y se detenía en los farallones indigenistas de Alegría y Argüedas. Es evidente el tufo ideológico de las décadas de hegemonía izquierdista que tuvo el discurso del magisterio. Tufo que no significó necesariamente buena lectura y mejor comprensión de aquellos

\section{1 un1Fé}


escritores transformados en íconos, sino que expulsó provisionalmente de la república de nuestras letras a Mario Vargas Llosa y a Alfredo Bryce (amén de otros escritores burgueses) por sus opiniones políticas.

Con la entronización del fujimorismo, el canon literario se vio influenciado por las miras pedagógicas del Banco Mundial y la poderosa influencia de las editoriales trasnacionales (fundamentalmente españolas) que, después de mucho tiempo, volvían a encargarse dela confección de libros escolares. Se reduce el acento reivindicador de ciertos íconos literarios, a los cuales se le agregan muchos más nombres. Por otro lado, los géneros literarios clásicos comparten casilleros con otras formas comunicativas que van del reportaje periodístico al cómic. Esta nueva oferta, presuntamente, proponía una visión educativa más plural; en la práctica fue un material curricular sobrecargado, casi imposible de dictar íntegramente durante el año escolar y que solo contribuyó a la despolitización general de la enseñanza ${ }^{2}$.

Y lo real es que el actual canon literario no es precisamente mucho más plural que antes (al demandar su contenido mucho más tiempo del existente en un plan curricular que desde los noventa empezó a penalizar las Humanidades), y más bien es una enorme despensa de la cual, por lo general, cada docente saca lo que quiere o lo que puede. Aún así, persiste el poco espacio dedicado a la poesía moderna o a las literaturas regionales, la renuencia a aproximarse a los experimentos e innovaciones delaliteratura durante el siglo XX y el hecho escandaloso que casi no se enseñe absolutamente nada de literatura quechua, aymara o de muchas etnias amazónicas, por más oral que parezca.

Sin una oferta accesible de libros para la gran mayoría de estudiantes, con un pobrísimo sistema de bibliotecas escolares y teniendo a mano sólo extractos de obras o desiguales antologías, se han perdido referencias literarias de todo tipo y nuestros estudiantes ya no tienen ni su autor favorito ni ese libro que les cambió la vida. Ese camino se le ha dejado libre a la cultura audiovisual de los estudiantes y - peor aún- al engendro de los manuales de autoayuda.

\section{III}

El plan lector es un intento desesperado del Estado por revertir lo evidente: sin una educación de calidad, nuestros niños están condenados a ser analfabetos funcionales y una mano de obra no calificada, sin criterio ni asertividad.

Como todo lo que se ha hecho en la educación peruana en los últimos veinticinco años, la propuesta del Plan lector se ha aplicado de forma irregular, incompleta y con poca ambición . Nunca se tomó en cuenta la posibilidad de una inversión masiva en bibliotecas escolares que sirvieran de reserva a la súbita alza de demanda lectora que provocó el Plan, tampoco se quiso aplicar otras posibilidades de fomentar la lectura mediante la transferencia directa de textos a los estudiantes y docentes (como se hace en sistemas educativos tan disímiles como los de Chile y Venezuela). Se prefirió dejar todo en manos del mercado y que el Estado actuara de forma residual prestando libros de resúmenes y extractos para los escolares de menores ingresos.

Sin embargo, el Plan lector abrió a la literatura peruana una insólita puerta de nuevos lectores (y, sobre todo, consumidores). la demanda de libros que no fueran los archiconocidos materiales de enseñanza, provocó que surgieran nuevas editoriales, se dieran a conocer nuevos escritores y se reciclaran varios ya consagrados. la literatura infantil y juvenil se ha convertido en el sector más dinámico de la literatura peruana, máxime si dentro de estos subgéneros se ha desarrollado una enorme producción de relatos e historias basadas en nuestro pasado y nuestra cultura. Desde Carlota Carvallo a Jorge Eslava, pasando por el gran Osear Colchado; tenemos ya una (joven) tradición en narrativa para niños y adolescentes . Es más, una generación de escritores del interior del Perú -casi todos ilustres desconocidos para la crítica y la prensa limeña- ha visto en el Plan lector un filón en el cual explotar su talento y que ha significado una mayor pluralidad en el consumo literario de los colegios, así como ha logrado que -en la práctica- los estudiantes de, por ejemplo, Ayacucho puedan leer literatura ayacuchana contemporánea. Frente a la marea avasalladora con que las editoras trasnacionales inundan los colegios privados y algunos selectos colegios nacionales, tenemos también una fuerte 
producción alternativa que viene de editoriales independientes y de escritores del interior del país. la calidad literaria peruana dio como resultado que las propias editoriales españolas no hayan tenido más remedio que fichar a escritores peruanos que hasta hace unos lustros, despreciaban.

Pero no todo es color de rosa. los escasos recursos con que pueden contar las familias que viven en pobreza y extrema pobreza marcan un límite inexorable en el consumo de libros y, por ende, en su participación dentro del Plan lector. la consecuencia no es solamente que los padres no compren nada y a sus hijos no les quede otro remedio que el parco menú lector que ofrece el Estado . El resultado es que una sostenida demanda que maneja un precio inelástico del libro termina atrayendo como solución una oferta compuesta por ediciones fenicias, pésimas copias piratas y libros tan mal diseñados e impresos que desaconsejan abiertamente sulectura . $_{3}$.

El Plan lector, pese a que puede contar con algunos errores, tiene grandes potencialidades. Sin embargo, sus beneficiosas consecuencias se reducen considerablemente cuando alcanzan a los sectores de bajos recursos que siguen siendo los excluidos de siempre. Para ellos, no hay nada nuevo bajo el sol y siguen padeciendo de una enseñanza convencional en lit erat ura con todos los males descritos anteriormente.

\section{IV}

la institución educativa es, por excelencia, un espacio fundamental ele socialización de niños y adolescentes. Desgraciadamente esto es asumido ele forma pasiva por los colegios. la falta de recursos reduce al mínimo las actividades extracurricularesy las arrincona de forma mecánica al calendario escolar dentro de gymkanas y desfiles. Solo los colegios llamados emblemáticos cuentan con clubes de ciencias, revistas propias, elencos de teatro, selecciones deportivas que no sean de fútbol e incluso algo parecido a un círculo ele ajedrecistas. Por lo general, las grandes actividades extracurriculares de los colegios públicos suelen ser cuatro: aniversario del colegio,jornadas lúdicas bajo la denominación de Semana de la Juventud u olimpiadas, el festidanza anual y el famoso desfile paramilitar por el 28de julio.

los juegos florales también son privativos de los colegios emblemáticos y fuera de éstos muy irregula res. Tampoco ayudan mucho las directivas del MINEDU que tienen poco entusiasmo en las convocatorias ele sus juegos florales nacionales o que ponen límites y condiciones sonrojantes a los $\mathrm{m}$ i $\mathrm{s} \mathrm{m} \mathrm{o} \mathrm{s}^{4}$. las actividades literarias extracurriculares (que van desde invitar a escritores hasta publicar la producción literaria ele los estudiantes) casi dependen del humor y la voluntad elelos profesores de Comunicación.

Además, las bibliotecas escolares suelen servir, en el mejor de los casos, como almacenes de maquetas, mapas y libros de texto. Dado que el profesor responsable de la biblioteca no suele tener ninguna capacitación en el manejo moderno de dicho espacio, su labor en la biblioteca no necesariamente lo posiciona mejor en el escalafón magisterial, ni tiene especial valoración en su foja de servicios, ni mucho menos recibe remuneración extra y más bien sobrecarga su agenda al asumir una tarea adicional a su cuota de horas de enseñanza; es muy difícil que encontremos profesores motivados para hacer de la biblioteca algo más que un depósito pasivo de libros. Por lo general, la biblioteca escolar tiene un aspecto testimonial,suele nofuncionar con la frecuencia que debería y en muchos colegios termina sellada durante años.

Todo esto hace que las posibilidades de una comunidad literaria ele estudiantes (esto es, de un grupo de estudiantes motivados e interesados en la lectura y en la praxis literaria) sean remotas en la gran mayoría de los colegios públicos. los estudiantes participan activamente en las competiciones deportivas, en las escoltas de los desfiles y hasta en las bandas de guerra de los colegios, creando sus propias comunidades y redes específicas, haciéndose además de un prestigio social dentro de la comunidad educativa. Pero, haciendo una odiosa comparación, no existe nada parecido a una comunidad literaria en la mayoría de los colegios públicos. No puede haberla porque no existen ni la estructura, ni los medios, ni los recursos, niel apoyoinstitucional. SinJuegos Florales donde se pueda premiar públicamente su producción literaria, con una biblioteca escolar raquítica en su contenido y catatónica en su funcionamiento, sin la posibilidad ele canalizar sus creaciones en algún tipo de publicación u otro medio informativo y sin actividades donde puedan aprender a desarrollar sus habilidades en las letras; los estudiantes que les guste y sepan escribir seguirán dispersos, marginados, decepcionados del poco valor quela comunidad le da asuscreaciones ${ }^{5}$.

\section{I un1Fé}


El caso se agrava si hablamos de estudiantes que provienen de familias conflictivas o que tienen que compaginar su rendimiento académico con actividades laborales y domésticas, todo en un ambiente de pobreza y extrema pobreza. Y no digamos del páramo de la educación rural, donde hay muchísimos más problemas de diversa índole por encima de los que hemos propuesto en este ensayo. Para esos estudiantes que arrastran ya problemas y hasta responsabilidades de adultos, la literatura -por ejemplo- podría ser un excelente instrumento de resiliencia y li beración. Eso, evidentemente, tampoco forma parte de las miras de la educación convencional dela literatura.

\section{V}

Muchos dirán que demasiados problemas tiene la educación peruana como para preocuparnos en las intimidades de la enseñanza curricular, la que -curiosamente- es la que lleva menos crítica dentro del enjuiciamiento general de la educación peruana. Se suele decir que fallan los profesores, fallan los directores, fallan las UGELs y hasta fallan los padres ele familia. En la lista de necesidades siempre primarán las inversiones en infraestructura y los salarios de los docentes. En los medios de comunicación y en la opinión pública, la impresión general es que un aumento general de inversiones en educación sumados a las nuevas generaciones de profesores (cada vez más despolitizados y más interesados en medrar en el sector privado) podrá revertir el desastre de nuestro sistema educativo.

Pues no. La realidad es mucho más compleja y la mejora de la educación peruana depende de mucho más indicadores, necesita de otras dinámicas y procesos en otros espacios que, sin ser directamente parte del sector educación, sí terminan coadyuvando en una mejora general. El sistema educativo no producirá mejores jóvenes si no es acompañado de una inversión en salud, de iniciativas que erradiquen el trabajo infantil en lo posible, de cambios en los hábitos nutricionales, de un ejercicio radical de ciudadanía, de una política cultural democrática y popular, etc. En la tarea del cambio educativo no sobra nadie.

En ese sentido, la necesidad ele mejorar la enseñanza de la literatura en nuestros colegios públicos no es una boutade, un puñado de consejos superfluos y, a la larga, prescindibles. Este ensayo no entiende la enseñanza de la literatura como algo superficial y colateral dentro del currículum . La enseñanza de la literatura va de la mano conla comprensión lectora, con el hábito de leer, con la formación de una metodología de aprendizaje eficaz que desarrolle en los estudiantes asertividad, pensamiento crítico e incluso empoderamiento. La literatura no es un adorno de los planes educativos institucionales, sino es partedeun proceso multidisciplinario, sinérgico y plural para hacer delos estudiantes, siquiera, buenos ciudadanos.

En ese sentido, señalamos la importancia que desde los estamentos docentes hasta las autoridades institucionales pueda significar un movinúento de renovación dela enseñanza de la literatura. Algo que no demanda muchos recursos ni implica desechar de plano los contenidos curriculares existentes: la posibilidad de enseñar literatura viva, conectar con las necesidades de los estudiantes y crear espacios y prácticas para que los estudiantes más motivados puedan desarrollar más sus habilidades, es básicamente un cambio de actitud del profesorado. La necesidad de ampliar la participación de los estudiantes y promover sus capacidades creativas es un compromiso de toda la institución educativa. Instalar y consolidar las bibliotecas escolares (amén de convertirlas en gestores de promoción cultural) es deber de toda la comunidad educativa. Claro que el Estado puede (y debe) ayudar en todas estas iniciativas, pero no es lícito esperar sentados a que esa ayuda alguna vez se aproxime.

Las décadas de pobreza, corrupción, violencia y discriminación que ha sufrido el Perú no han matado su literatura. Mentira que los colegios peruanos pobres estén condenados a administrar un ganado que no pasará de ser en el futuro mano ele obra ignorante y bruta. Cuando viajo y me detengo en los colegios públicos de las pedanías de provincia o cuando recorro las escuelas desvencijadas de la Lima excluida, siempre he visto estudiantes valiosos, críticos, con ganas de avanzar. Y también he visto el genio artístico y la raza ele poetas en los ojos ele muchos de ellos. Unas potencialidades que no solamente se truncan por la miseria, la enfermedacl y la falta de oportunidades; sino también porque en su propio colegio ya encuentra límites y obstáculos.

Necesitamos ejércitos de poetas y escritores. Y los tenemos. Solo hace falta crear condiciones para que ellos se den a conocer, avancen y lleguen a volar por sí solos. Quizá nosotros no terminemos siendo la literatura que el país necesita, pero sí podemos ayudar a que nuestros adolescentes escriban -bastante mejor que nosotros- la futura literatura del Perú. 


\section{NOTAS}

(l) Oliart,Patricia(2011).Políticaseducativasylaculturadel sistema escolaren el Perú . Lima: Tarea/IEP.

(2) Para un análisis de la utilidad práctica que tiene el diseño de los textos de literatura (sobre todo su enorme extensión en actividades y tareas), está la ponencia de Gina Moore Carranza para el VII Congreso Nacional de Lengua y Literatura en Huamanga en el 2010: Entidades discursivas en los textos escolares de comunicación primaria: entre el orden y la sugerencia compilada en Esenc ia de la palabra: VII Congreso Nacional Lingiiístico Literario"Ricardo Gonzales Vigi/"(Lima:Ed.

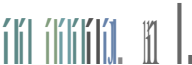

(3) Por poner ejemplos: el precio de un libro de texto de una editora especializada en educación ondea de 30 a 60 soles, las ediciones piratas pueden conseguirse por 15 soles aproximadamente. En la zona de Pamplona Alta, en el distrito limeño de San Juan de Miraflores, las familias no ganan más de 300 soles mensuales y en los colegios señalan que los padres de familia declararon no poder (o no querer) gastar más de 2.50soles por libro.

(4) En la convocatoria de los Juegos Florales Nacionales del 2010 para todos los colegios de Lima, el Ministerio hacía estas vergonzosas advertencias: "Se recomienda que los estudiantes compongan poemas con temática que reflejen la esperanza, el amor, el optimismo, la pujanz a, el valor, la hernicidad, la s raíces históricas de la nación peniana, la dignidad y el orgu11o colectivo del pueblo; descartándose poemas con temáticas lastimeras, pesimistaso

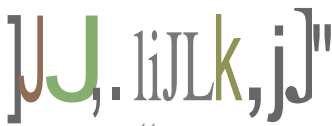

]$\left._{11}\right]_{1,1}^{1}$ a poeta,pcrna,o,

enesalinea ${ }^{11}$.

(S) Esta ausencia de una comunidad literaria es extensible al caso de los estudiantes motivados en matemáticas, ciencias natu rales o artes plásticas, huérfanos de sus respectivas comunidades.

\section{Soc. Javier Garvích Rebatta}

Sociólogo por la PUCP. Ha sido docente en la Escuela Superior de Periodismo Bauzate y Mesa. Fundador y director de Ouipu en España. Ha colaborado con diversos periódicos y fue codirector del Programa Cultural de Radio Cielo Dos palabras al viento. Es editor de la Revista Peruana de Literatura y tiene a su cargo el blog El lápiz y el martillo (http://lapizymartillo. blogspot.com). 